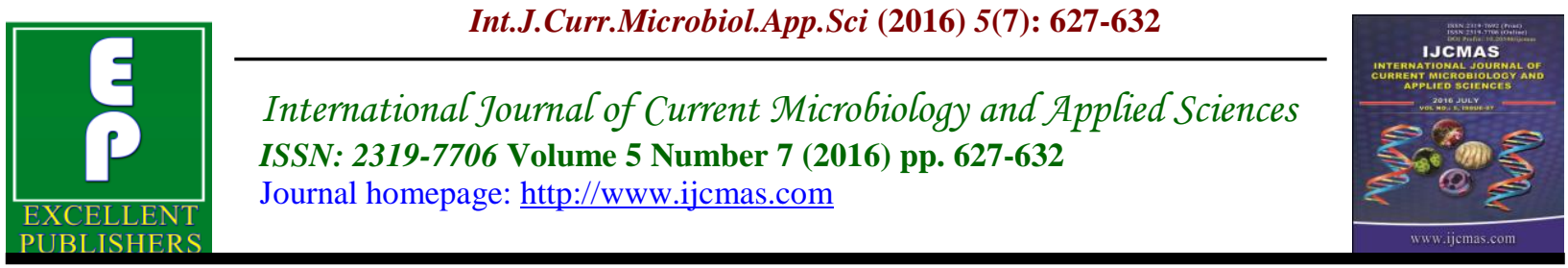

Original Research Article

http://dx.doi.org/10.20546/ijcmas.2016.507.070

\title{
Emergence of Drug Resistant Fungi in Hospital Air: A Need for Strict Microbiological Surveillance
}

\author{
K.L. Seervi*, P.K. Khatri, R.S. Parihar, Smita Kulshrestha, \\ Saroj Meena and Archana Bora
}

\author{
Department of Microbiology, Dr. S.N. Medical College, Shastri Nagar Jodhpur-342003 \\ Rajasthan, India \\ *Corresponding author
}

Keywords

Drug resistant

fungi,

fungal

nosocomial

infections,

fungaemia.

\section{Article Info}

Accepted:

20 June 2016

Available Online:

10 July 2016

\section{A B S T R A C T}

Fungal infections of hospital origin have been gaining importance in recent years due to their progressive increase with high rate of morbidity and mortality. Our study reports the results of environmental surveillance of fungi in specific areas of two tertiary care hospitals of Dr. S.N. Medical College, Jodhpur-Rajasthan. Study was conducted from January2015 to 2016. Samples from the air of two local tertiary care hospitals were collected on a monthly basis. The air sampling was done by passive sedimentation method on petriplates containing Sabouraud's dextrose agar medium supplemented with gentamycin for one hour in respective areas then sealed and sent to the Department of Microbiology for processing by standard microbiological procedures. This study find out different contamination levels at different areas of hospital with100 fungal isolates: Candida albicans (n =22), C.parapsilosis $(\mathrm{n}=15)$, Candida tropicalis $(\mathrm{n}=5)$, Rhodotorula $(\mathrm{n}=2)$, Trichosporon ( $\mathrm{n}=1)$, Aspergillus spp.( $\mathrm{n}=45)$, Mucor spp. $(\mathrm{n}=5)$ \& Penicillium spp.(n=5). In general most of these isolates were found to be resistant to Flucanazole, Itraconazole \& Clotrimazole while Voriconazole is still most sensitive. Opportunistic mycoses have been increased in recent years in our study as well as international health facilities. In our findings, C.albicans, Candida parapsilosis, non-Candida yeast species \& many moulds were common which might be coming from human clinical material as well as from environmental samples. Results of our study were very similar to Raimunda Sâmia N. Brilhante et al study. Our study emphasize on strict hospital environmental monitoring for fungi to prevent possible fungal nosocomial infections because of our negligence about air contaminants fungi may causes severe opportunistic fungaemia with very high morbidity \& mortality.

\section{Introduction}

The importance of bio-aerosols has been emphasized in recent decades due to their effect on human health (Gangneux et al., 2006). These particles act as transmitters of hospital infections (Dacarro et al., 2003; Afonso et al., 2006), as they act as epidemiologic markers of microbial contamination (Brasil et al., 2000). Fungal 
infections of hospital origin have been gaining importance in recent years due to their progressive increase and their high rates of morbidity and mortality (Pfaller, 1996; Centeno et al., 2004). In the hospital environment, the airborne micro biota is formed mainly by filamentous fungi, especially the genera Aspergillus, Penicillium \& Mucor (Rainer et al., 2001; Sanca et al., 2002) Yeasts of the genera Candida, Rhodotorula, and Trichosporon (Krajewska et al., 2004; Pini et al., 2005; Wang et al., 2005), all have been described as potential human pathogens \& the important causative agent of hospital fungaemia (Moretti, 2007). The passive sedimentation technique is still widely recommended in the literature for use as a microbiological alert. Bio-aerosol monitoring in hospitals can provide information for epidemiological investigation of nosocomial infectious diseases and research in airborne microorganism spread and control, as well as for quality control measures (Moretti, 2007). This study involved the environmental monitoring of fungi in specific areas of two tertiary level hospitals.

\section{Materials and Methods}

The present study was conducted at Department of Microbiology, Dr. S.N. Medical College Jodhpur \& attached group of Hospitals- Rajasthan. Air sampling from different areas of hospitals was performed at regular interval using the passive sedimentation method in $90 \mathrm{~mm}$ diameter 300 Petri dishes containing Sabouraud's dextrose agar medium supplemented with gentamycin. The plates were exposed in each of the environments for one hour positioned 2 meters high - roughly human respiration height (Pei-Chih et al., 2000). The Petri dishes were sealed and sent to the Department of Microbiology.
The samples were kept at $25^{\circ} \mathrm{C}$ to $28{ }^{\circ} \mathrm{C}$ in B.O.D. incubator and examined after 48 hours to a week or so till any fungal growth appeared. Different colonies of white, black, green and brown or cream colour were obtained. Yeasts were identified by germ tube test, characteristics morphology on Glucose agar- $0.1 \%$, culture characteristics on $\mathrm{HI}$ chrome agar (HI media, Mumbai, India) \& confirmed by Automated Vitek-2 compact system.

Moulds were identified by texture \&colour of the obverse \& reverse surface of colony, Lactophenol cotton blue mount preparation \& morphology found on slide culture. (Moline et al, 1999; Duguid et al, 1999; Forbes et al., 2002; Freydiere et al., 2001)

The antifungal susceptibility of the isolates was done by using CLSI M44 A-2 Disc diffusion method for Yeast on Mueller Hinton Agar with $2 \%$ glucose $\& 0.5 \mu \mathrm{g} / \mathrm{ml}$ methylene blue \& CLSI M38 A-2 broth micro-dilution method for Moulds. ${ }^{16}$ (NCCLS 2004) Quality control was performed using standard strains of Candida parapsilosis ATCC 22019 for Yeasts \& Aspergillus flavus ATCC204304 for Moulds.

\section{Results and Discussion}

A total of 300 air samples from 5 hospital environments were analyzed, from which 100 strains of fungi were isolated out of them Candida albicans ( $\mathrm{n}=22$ ), C.parapsilosis $(\mathrm{n}=15)$ Candida tropicalis $(\mathrm{n}=5)$ Rhodotorula $(\mathrm{n}=2)$, Trichosporon ( $\mathrm{n}$ $=1)$ Aspergillus spp. $(\mathrm{n}=45)$ Mucor spp.(n=5) Penicillium spp. $(\mathrm{n}=5)$ were found as shown in Table-1 \& Bar diagram. 
Table.1 Frequency of fungi found in air of different areas of Hospital

\begin{tabular}{|c|c|c|c|c|c|c|c|c|c|}
\hline $\begin{array}{l}\text { Area of } \\
\text { sampling }\end{array}$ & $\begin{array}{l}\text { No. of } \\
\text { petriplates }\end{array}$ & $\begin{array}{l}\text { Candida } \\
\text { albicans } \\
\text { F\% }\end{array}$ & $\begin{array}{l}\text { Candida } \\
\text { parapsilosis } \\
\text { F\% }\end{array}$ & $\begin{array}{l}\text { Candida } \\
\text { tropicalis } \\
\text { F\% }\end{array}$ & $\begin{array}{l}\text { Rhodotorula } \\
\text { F\% }\end{array}$ & $\begin{array}{l}\text { Trichosporon } \\
\text { capitatum F\% }\end{array}$ & $\begin{array}{l}\text { Aspergillus } \\
\text { spp. F\% }\end{array}$ & $\begin{array}{l}\text { Penicillium } \\
\text { spp. F\% }\end{array}$ & $\begin{array}{l}\text { Mucor } \\
\text { spp. } \\
\text { F\% }\end{array}$ \\
\hline $\begin{array}{l}\text { ICU of } \\
\text { MGH }\end{array}$ & 60 & 10 & 20 & 00 & 00 & 05 & 55 & 05 & 05 \\
\hline $\begin{array}{l}\text { Burn } \\
\text { unit of } \\
\text { MGH }\end{array}$ & 60 & 20 & 20 & 10 & 05 & 00 & 40 & 00 & 05 \\
\hline $\begin{array}{l}\text { ICU of } \\
\text { MDMH }\end{array}$ & 60 & 15 & 20 & 15 & 05 & 00 & 40 & 00 & 05 \\
\hline $\begin{array}{l}\text { Swine flu } \\
\text { ICU of } \\
\text { MDMH } \\
\end{array}$ & 60 & 50 & 00 & 00 & 00 & 00 & 40 & 10 & 00 \\
\hline
\end{tabular}

MGH-Mahatma Gandhi Hospital, MDMH-Mathuradas Mathur Hospital Jodhpur

Table.2 Resistance pattern of Candida albicans isolates in \%

\begin{tabular}{|l|l|l|l|l|l|l|l|l|}
\hline Area of hospital & FLC & VRC & IT & AP & NS & CC & KTZ & MIC \\
\hline ICU of MGH & 75 & 00 & 75 & 25 & 35 & 50 & 50 & 50 \\
\hline Burn unit of MGH & 50 & 00 & 50 & 25 & 40 & 80 & 50 & 40 \\
\hline RRC OT of MGH & 75 & 10 & 50 & 20 & 25 & 60 & 25 & 50 \\
\hline ICU of MDMH & 100 & 10 & 50 & 30 & 50 & 60 & 25 & 50 \\
\hline $\begin{array}{l}\text { Swine flu ICU of } \\
\text { MDMH }\end{array}$ & 100 & 20 & 75 & 50 & 50 & 50 & 50 & 60 \\
\hline
\end{tabular}

FLC-Flucanazole, VRC-Voriconazole, IT-Itraconazole, AP-AmphotericinB NS-Nystatin, CC-Clotrimazole, KTZ-Ketoconazole, MIC-Miconazole 
Table.3 Resistance pattern of Candida parapsilosis isolates in \%

\begin{tabular}{|l|l|l|l|l|l|l|l|l|}
\hline Area of hospital & FLC & VRC & IT & AP & NS & CC & KTZ & MIC \\
\hline ICU of MGH & 50 & 00 & 50 & 25 & 25 & 50 & 50 & 40 \\
\hline Burn unit of MGH & 100 & 10 & 75 & 35 & 50 & 80 & 50 & 50 \\
\hline RRC OT of MGH & 50 & 10 & 50 & 10 & 25 & 55 & 25 & 50 \\
\hline ICU of MDMH & 100 & 10 & 50 & 30 & 50 & 40 & 25 & 50 \\
\hline Swine flu ICU of MDMH & 100 & 10 & 75 & 50 & 50 & 75 & 50 & 60 \\
\hline
\end{tabular}

Table.4 Resistance pattern of Aspergillus spp. Isolates

\begin{tabular}{|l|l|l|l|l|l|l|l|l|}
\hline Area of hospital & FLC & VRC & IT & AP & NS & CC & KTZ & MIC \\
\hline ICU of MGH & 80 & 00 & 50 & 25 & 25 & 75 & 20 & 30 \\
\hline Burn unit of MGH & 100 & 20 & 75 & 50 & 50 & 100 & 50 & 40 \\
\hline RRC OT of MGH & 75 & 10 & 50 & 20 & 25 & 60 & 25 & 40 \\
\hline ICU of MDMH & 75 & 10 & 50 & 25 & 25 & 75 & 40 & 50 \\
\hline Swine flu ICU of MDMH & 90 & 20 & 75 & 50 & 50 & 80 & 60 & 40 \\
\hline
\end{tabular}

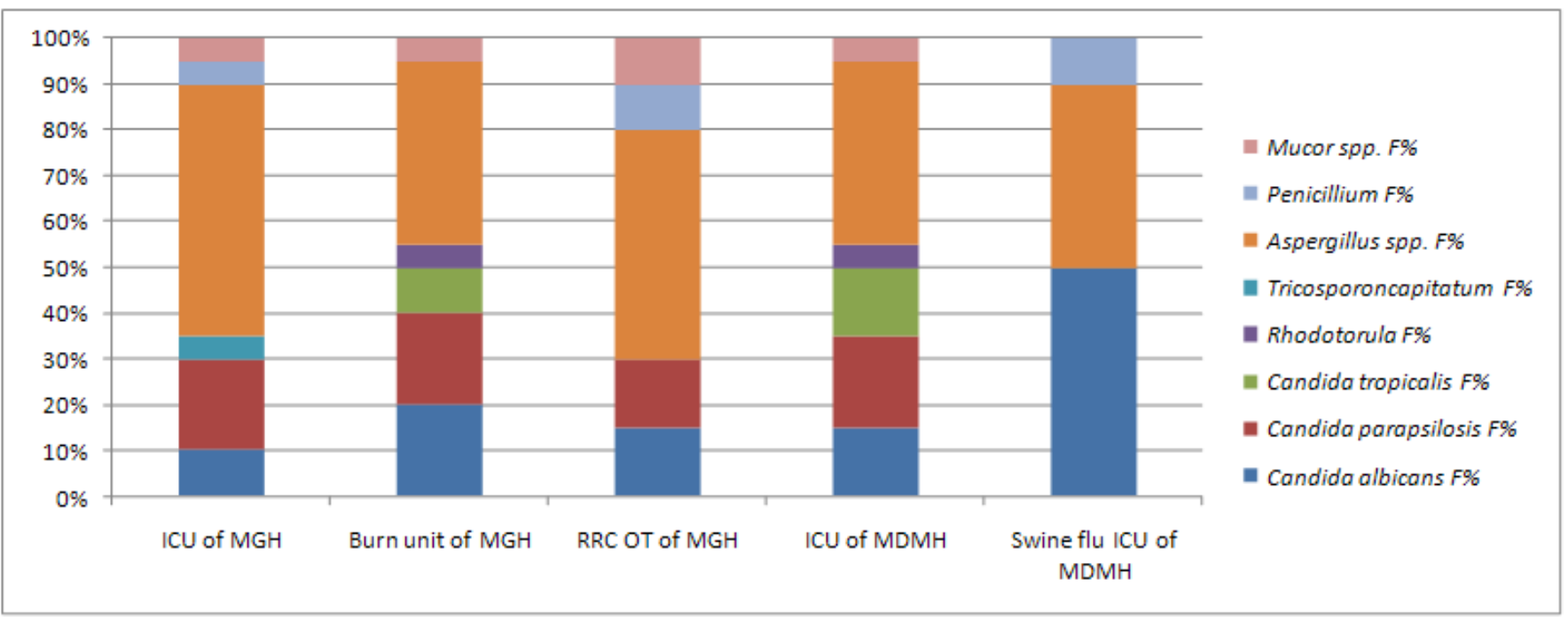

Bar diagram.1 showing Frequency of fungi found in air of different areas of Hospital

Regarding resistance pattern of isolates $80 \%$ Candida albicans and C.parapsilosis were resistant to Flucanazole, $60 \%$ to Itraconazole \& Clotrimazole, $50 \%$ to Miconazole, $40 \%$ to Nystatin \& Ketoconazole, while Voriconazole was found to be most sensitive in $>90 \%$ followed by AmphotericinB in $70 \%$ isolates as shown in Table- 2 and 3.

According to the literature, airborne particles can have many origins (Moscato, 2000). In environments with artificial ventilation, the air conditioning system, due to condensation trays, has been considered an important source of microorganism distribution. Thus, in environments with artificial ventilation, yeasts are probably transmitted by droplets produced by bioaerosol equipment, as well as by coughing or sneezing, or even by routine procedures such as the withdrawal of vascular catheters. However, in environments with natural ventilation, the principal origins of air particles are believed to be ventilators, 
nebulizers, air humidifiers, plant vases, some foods, and people themselves.

In conclusion, observations of our study strictly recommended that air monitoring is essential to prevent hospital infections. Among the preventive measures that should be considered are:- Good quality fumigation at regular interval, more frequent mechanical removal of dust, cleaning \& mopping of floor \& permanent items with disinfectant on daily basis, restriction of entry, better cleaning and maintenance of air conditioners and other equipment that produce bio-aerosols, correction of room humidity, use of protective clothing by hospital personnel, and better staff training regarding the threats of infection by airborne microorganisms.

\section{Acknowledgements}

We express grateful thanks to Principal \& Controller \& HODs of respective Departments of Mahatma Gandhi Hospital \& Mathuradas Mathur Hospital of Dr. S.N. Medical College Jodhpur, Rajasthan.

\section{References}

Afonso, M.S.M., Souza, A.C.S., Tipple, A.F.V., Machado, E.A., Lucas, E.A. 2006. Condicionamento de ar em salas de operação e controle de infecção - uma revisão. Rev Eletr Enf, 8: 134-43.

Alberti, C., Bouakline, A., Ribauad, P. et al. 2001. Relationship between environmental fungal contamination and the incidence of invasive aspergillosis in hematology patients. $J$. Hosp. Infect., 48: 198-206.

Brasil, Ministério da Saúde Resolução. n.176, 24 out. 2000. Agência Nacional de Vigilância Sanitária. Orientação técnica sobre padrões referenciais de qualidade do ar interior em ambientes climatizados artificialmente de uso público e coletivo 2000. (Of. El. N.370/2000).

Calderone, R.A., Fonzi, W.A. 2001. Virulence factors of Candida albicans. Trends Microbiol., 9: 327-35.

Centeno, S., Machado, S. 2004. Assessment of airbone mycoflora in critical areas of the principal hospital of Cumaná, state of Sucre, Venezuela Invest Clin., 45: 137-44.

Colombo, A.L. 2000. Epidemiology and treatment of hematogenous candidiasis: a Brazilian perspective. Braz J. Infect. Dis., 4: 113-8.

Dacarro, C., Picco, A.M., Grisoli, P., Rodolfi, M. 2003. Determination of aerial microbiological contamination in scholastic sports environments. $J$. Appl. Microbiol., 95: 904-12.

Gangneux, J.P., Bousseau, A., Cornillet, A., Kauffmann-Lacroix, C. 2006. Control of fungal environmental risk in French hospitals. J. Mycol. Médicale, 16: 20411.

Krajewska, K., Krajewska-Kulak, E., Lukaszuk, C., Rolka, H., Lach, J., Karczewski, J. 2004. Occurrence of fungal pathogens in the delivery rooms of a hospital obstetrics department. Ginekol Pol., 75: 451-6.

Li, C., Hou, P. 2003. Bio-aerosol characteristics in hospital clean rooms. The Sci of the Total Environ., 305: 169-76.

Mathews, M.S., Samuel, P.R., Suresh, M. 2001. Emergence of Candida tropicalis as the major cause of fungaemia in India. Mycoses, 44: 278-280.

Medrano, D.J.A., Brilhante, R.S.N., Cordeiro, R.A., Rocha, M.F.G., Rabenhorst, S.H.B., Sidrim, J.J.C. 2006. Candidemia in a brazilian hospital: the importance of Candida parapsilosis. Rev. Inst. Med. Trop. São Paulo, 48: 17-20. 
Moretti, M.L. 2007. A importância crescente das infecções fúngicas. Rev. Panam Infectol., 9: 8-9.

Moscato, U. 2000. Hygienic management of air conditioning systems. Ann. Ig., 12: 155-74.

NCCLS. 2004. National Committee of Clinical and Laboratory Standards) Performance standard for antimicrobial susceptibility testing; $14^{\text {th }}$ informational supplement. NCCLS document M100-S14, M27A2. 2nd ed. Wayne, Pa: Reference method for broth dilution testing of yeast approved standard. West Valley, Pennsylvania, USA.

Nguyen, M.H., Peacock, J.E., Morris, A.J. et al. 1996. The changing face of candidemia: emergence of nonCandida albicans species and antifungal resistance. Am. J. Med., 100: 617-23.

Owers, K.L., James, E, Bannister, G.C. 2004. Source of bacterial shedding in laminar flow theatres. J. Hosp. Infect., 58: $230-2$.

Pei-Chih, W., Huey-Jen, S., Chia-Yin, L. 2000. Characteristics of indoor and outdoor airbone fungi at suburban and urban homes in two seasons. The Sci. of the Total Environ., 253: 111-8.

Pfaller, M.A. 1996. Nosocomial candidiasis: emerging species, reservoir, and modes of transmission. Clin. Infect.
Dis., 22: 89-94.

Pfaller, M.A., Yu, W.L. 2001. Antifungal susceptibility testing- New technology and clinical applications. Infect. Dis. Clin. N. Am., 15: 1227-61.

Pini, G., Faggi, E., Donato, R., Fanci, R. 2005. Isolation of Trichosporon in a hematology ward. Mycoses, 48: 45-9.

Pletinex, M., Legein, J., Vandenplas, Y. 1995. Fungemia with Saccharomyces boulardii in a 1-year-old-girl with protacted diarrhea. J. Pediatr. Gastroenterol. Nutr., 21: 113-5.

Rainer, J., Peintner, U., Pöder, R. 2001. Biodiversity and concentration of airbone fungi in a hospital environment. Mycopathologia, 149: 87-97.

Sanca, S., Asan, A., Otkun, M.T., Ture, M. 2002. Monitoring Indoor Airborne Fungi and Bacteria in the Different Areas of Trakya University Hospital, Edirne, Turkey. Indoor Built Environ., 11: 285-92.

Wang, C.Y., Wu, H.D., Hsueh, P.R 2005. Nosocomial transmission of cryptococcosis. N. Engl. J. Med., 352: 1271-2.

Weems, J.J. 1992. Candida parapsilosis: epidemiology, pathogenicity, clinical manifestations and antimicrobial susceptibility. Clin. Infect. Dis., 14: 756-66.

\section{How to cite this article:}

Seervi, K.L., P.K. Khatri, R.S. Parihar, Smita Kulshrestha, Saroj Meena and Archana Bora. 2016. Emergence of Drug Resistant Fungi in Hospital Air: A Need for Strict Microbiological Surveillance. Int.J.Curr.Microbiol.App.Sci. 5(7): 627-632. doi: http://dx.doi.org/10.20546/ijcmas.2016.507.070 